OPEN ACCESS

Edited by:

Katy Rezvani,

University of Texas MD Anderson Cancer Center, United States

Reviewed by: Takuya Sekine, University of Oxford,

United Kingdom

Rayne Rouce,

Baylor College of Medicine,

United States

*Correspondence:

Cristina Eguizabal cristina.eguizabalargaiz@ osakidetza.eus

Specialty section: This article was submitted to Cancer Immunity and Immunotherapy,

a section of the journal

Frontiers in Immunology

Received: 02 March 2017 Accepted: 14 June 2017

Published: 30 June 2017

Citation:

Herrera L, Salcedo JM, Santos S, Vesga MÁ, Borrego F and Eguizabal C (2017) OP9 Feeder Cells Are Superior to M2-10B4 Cells for the Generation of Mature and Functional Natural Killer Cells from Umbilical Cord Hematopoietic Progenitors.

Front. Immunol. 8:755. doi: 10.3389/fimmu.2017.00755

\section{OP9 Feeder Cells Are Superior to M2-10B4 Cells for the Generation of Mature and Functional Natural Killer Cells from Umbilical Cord Hematopoietic Progenitors}

\author{
Lara Herrera ${ }^{1}$, Juan Manuel Salcedo', Silvia Santos ${ }^{1}$, Miguel Ángel Vesga', Francisco \\ Borrego $^{2,3,4}$ and Cristina Eguizabal ${ }^{1 *}$
}

${ }^{1}$ Cell Therapy and Stem Cells Group, Basque Center for Transfusion and Human Tissues, Galdakao, Spain, ${ }^{2}$ Research Unit, Basque Center for Transfusion and Human Tissues, Galdakao, Spain, ${ }^{3} /$ mmunopathology Group, BioCruces Health Research Institute, Barakaldo, Spain, ${ }^{4} / k e r b a s q u e$, Basque Foundation for Science, Bilbao, Spain

Adoptive natural killer (NK) cell therapy relies on the acquisition of large numbers of mature and functional NK cells. An option for future immunotherapy treatments is to use large amounts of NK cells derived and differentiated from umbilical cord blood (UCB) CD34+ hematopoietic stem cells (HSCs), mainly because UCB is one of the most accessible HSC sources. In our study, we compared the potential of two stromal cell lines, OP9 and M2-10B4, for in vitro generation of mature and functional CD56+ NK cells from UCB CD34+ HSC. We generated higher number of CD56 ${ }^{+} \mathrm{NK}$ cells in the presence of the OP9 cell line than when they were generated in the presence of M2-10B4 cells. Furthermore, higher frequency of CD56 ${ }^{+} \mathrm{NK}$ cells was achieved earlier when cultures were performed with the OP9 cells than with the M2-10B4 cells. Additionally, we studied in detail the maturation stages of $\mathrm{CD}^{2} 6^{+} \mathrm{NK}$ cells during the in vitro differentiation process. Our data show that by using both stromal cell lines, CD34+ $\mathrm{HSC}$ in vitro differentiated into the terminal stages 4-5 of maturation resembled the in vivo differentiation pattern of human NK cells. Higher frequencies of more mature NK cells were reached earlier by using OP9 cell line than M2-10B4 cells. Alternatively, we observed that our in vitro NK cells expressed similar levels of granzyme B and perforin, and there were no significant differences between cultures performed in the presence of OP9 cell line or M2-10B4 cell line. Likewise, degranulation and cytotoxic activity against K562 target cells were very similar in both culture conditions. The results presented here provide an optimal strategy to generate high numbers of mature and functional NK cells in vitro, and point toward the use of the OP9 stromal cell line to accelerate the culture procedure to obtain them. Furthermore, this method could establish the basis for the generation of mature NK cells ready for cancer immunotherapy.

Keywords: hematopoietic stem cells, umbilical cord blood, natural killer cells, in vitro cell differentiation, immunotherapy 


\section{INTRODUCTION}

Natural killer (NK) cells constitute $10-15 \%$ of peripheral blood (PB) lymphocytes and display a half-life of approximately 7-10 days in circulation (1). They can also be found in cord blood (CB) in a similar frequency to $\mathrm{PB}(2)$, but the small volume in $\mathrm{CB}$ units represents the difficulty in obtaining suitable numbers of NK cells needed for clinical use (3). Human NK cells are phenotypically described as $\mathrm{CD}^{-}{ }^{-} \mathrm{CD} 56^{+}$cells within the lymphocyte population (4), and they are classified as a subset within the group 1 of innate lymphocyte cells, capable of producing IFN- $\gamma$, and exert cytotoxicity (5). According to the intensity of the expression of the CD56 receptor, in vivo differentiated mature NK cells are divided into CD56 $6^{\text {bright }}$ and CD56 $6^{\text {dim }}$ subpopulations (6). CD56 bright cells constitute less than $10 \%$ of circulating NK cells, produce high levels of inflammatory cytokines, and have none or low expression of CD16. CD56 ${ }^{\mathrm{dim}} \mathrm{NK}$ cells express CD16 and contain an abundance of granules that arm them for cytolytic activity against viral-infected and cancer cells (7). NK cells are originated from $\mathrm{CD} 34^{+}$hematopoietic progenitors (4). Before reaching a mature stage, they acquire progressively and orderly different surface markers, being classified into stage 1 $\left(\mathrm{CD} 34^{+}, \mathrm{CD} 45 \mathrm{RA}^{+}, \mathrm{CD}_{117^{-}}, \mathrm{CD}^{-} 4^{-}, \mathrm{CD}^{-} 6^{-}, \mathrm{CD}^{-} 6^{-}\right)$, stage 2

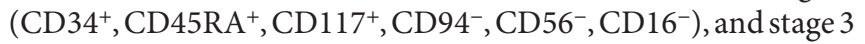
$\left(\mathrm{CD} 34^{-} \mathrm{CD} 117^{+}, \mathrm{CD} 94^{-}, \mathrm{CD} 56^{-}, \mathrm{CD} 16^{-}\right)$. Once they reach a mature stage, NK cells are phenotypically described by their surface markers as stage $4\left(\mathrm{CD} 34^{-}, \mathrm{CD} 94^{+}, \mathrm{CD} 117^{+-}, \mathrm{CD} 56^{\text {bright }}\right.$, $\left.\mathrm{CD} 16^{+/-}\right)$and stage $5\left(\mathrm{CD} 34^{-}, \mathrm{CD} 94^{+/-}, \mathrm{CD} 117^{-}, \mathrm{CD} 56^{\mathrm{dim}}\right.$, $\left.\mathrm{CD}^{+} 6^{+}\right)(8)$.

Current NK cell-based cancer immunotherapy aims to reverse the tumor-induced NK cell dysfunction that is observed in patients with cancer and to increase and sustain NK cell effector functions $(9,10)$. The low numbers of these cells in PB and, even lower numbers in $\mathrm{CB}$, have led to several approaches to expand and/or activate freshly isolated autologous or allogeneic NK cells by culturing with different interleukins, such as IL-2, IL-15, and IL-21 (11-14). CD34+ hematopoietic progenitors from umbilical cord blood (UCB) are being considered a source for the production of a large number of NK cells $(15,16)$. Obtaining NK cells from UCB CD $34^{+}$hematopoietic progenitors has been extensively described (17). However, further research is needed to obtain even larger numbers of mature and functional NK cells ready to use in cancer immunotherapy.

In this study, we aimed to evaluate the production of functional and mature NK cells from UCB CD $34^{+}$hematopoietic progenitors with two different culture conditions, where OP9 and M2-10B4 cell lines are used as feeder layers. OP9 is typically used as a support for the differentiation of CD34 ${ }^{+}$ cells from embryonic stem cells (ESCs) or pluripotent stem cells (18-21). Instead, M2-10B4 is a good support to maintain $\mathrm{CD}^{2} 4^{+}$cells in a long-term culture, acting like a hematopoietic niche (22). Our data show that these two culture conditions generated a large number of mature and functional NK cells. Furthermore, the presence of OP9 feeder cells in the culture generated a higher amount of mature NK cells in a faster manner when compared with culture conditions with M2-10B4 feeder cells.

\section{MATERIALS AND METHODS}

\section{Umbilical Cord and PB Samples and Cell Lines}

Umbilical cord blood and PB samples were obtained with prior signed informed consent and ethical committee approval from the Basque Ethics Committee for Clinical Research [Comité Etico de Investigación Clinica de Euskadi-CEIC-E (PI2014138)]. Fully signed written informed consent was obtained from the pregnant mothers. UCB units that contain between $1.5 \times 10^{9}$ and $8 \times 10^{8}$ mononuclear cells were used for investigation purposes. One fresh UCB unit (less than $30 \mathrm{~h}$ between the extraction and the processing) was used to perform a set of experiments (Table S1 in Supplementary Material). OP9, M2-10B4, and K562 cell lines were purchased from ATCC (CRL-2749, CRL-1972, and CCL-243, respectively). OP9 cells were cultured with $\alpha$-MEM (Gibco), 20\% fetal bovine serum (FBS) (Hyclone), 1\% penicillin/streptomycin, and 1\% Glutamax. M2-10B4 cells were culture with RPMI, 10\% FBS (Hyclone), 1\% penicillin/streptomycin, and $1 \%$ Glutamax. Finally, K562 cells were cultured with RPMI, 10\% FBS (Hyclone), 1\% penicillin/streptomycin, 1\% Glutamax, $1 \%$ NEAA, and $1 \%$ sodium pyruvate.

\section{Hematopoietic Stem Cell (HSC) Differentiation Protocol into NK Cells}

Umbilical cord blood mononuclear cells were obtained by density gradient using Ficoll-Paque ${ }^{\mathrm{TM}}$ PLUS (GE Healthcare). Then, HSCs were isolated by MACS sorting, using the CD34 MicroBead kit from Miltenyi Biotec. CD34 ${ }^{+}$cells (5,000 cells/well) were plated onto 6-well plates coated with OP9 or M2-10B4 cells inactivated with Mitomycin C $(10 \mu \mathrm{g} / \mathrm{ml})$ (Sigma) and plated in feeder-free system and cultured with the media described by $\mathrm{Ni}$ et al. (23): Ham F12 $2^{+}$DMEM (1:2), 20\% human serum (AB serum-Invitrogen, Life Technologies), 1\% penicillin/streptomycin, 2-mercaptoethanol $(25 \mu \mathrm{M})$, ascorbic acid $(20 \mu \mathrm{g} / \mathrm{ml})$, and sodium selenite $(5 \mathrm{ng} / \mathrm{ml})$. At the beginning of the differentiation process, IL-3 (5 ng/ml), IL-7 (20 ng/ml), IL-15 (10 ng/ml), SCF $(20 \mathrm{ng} / \mathrm{ml})$, and FLT3 ligand $(10 \mathrm{ng} / \mathrm{ml})$ (Miltenyi Biotec) were added to the medium. Half of the medium was changed every week. From the second week of differentiation, IL-3 was no longer added to the medium as was described by Cichocki and Miller (24) and Grzywacz et al. (25). The differentiation protocol that we carried out consisted of plating purified $\mathrm{CD} 34^{+}$cells over two different culture conditions using two feeder cells layers, OP9 and M2-10B4, and cultured for 42 days with the differentiation medium previously described. From day 14 up to day 42 of differentiation, immunophenotype analyses were performed, along with cytotoxicity and degranulation assays at 28,35 , and 42 days of differentiation.

\section{Flow Cytometry Analysis}

Purity of $\mathrm{CD}_{3} 4^{+}$sorted cells from UCB samples was analyzed with CD34-PE antibody (BD Biosciences, clone 581) in a FACS Canto II (BD Biosciences). Purity of the $\mathrm{CD} 34^{+}$cells isolated had to be higher than $80 \%$ in order to perform our protocol of differentiation (Figure S1A in Supplementary Material). The 
number of remaining $\mathrm{CD} 56^{+}$cells in the purified sample was not significant (Figure S1B in Supplementary Material).

Different populations and maturation stages of in vitro differentiated NK cells were analyzed by flow cytometry at 14, 21, 28,35 , and 42 days in culture. Cells were washed with PBS/10\% FBS and incubated for $30 \mathrm{~min}$ at $4^{\circ} \mathrm{C}$ for labeling with antiCD94-FITC (BD Biosciences, clone HP-3D9), anti-CD117-PE (Miltenyi Biotec, clone A3C6E2), anti-CD56-APC (Biolegend, clone MEM-188), and anti-CD16-BV421 (BD Biosciences, clone 3G8). Next, cells were fixed and permeabilized with BD Cytofix/ Cytoperm $^{\mathrm{TM}}$ Plus in order to label them with anti-PerforinPerCP-eF710 (BD Biosciences, clone $\delta$ G9) and anti-Granzyme B-BV510 (BD Biosciences, clone GB11). 50,000-100,000 events were acquired for analyses. Populations were analyzed using FlowJo v.X.0.7 (TreeStar Inc.).

\section{Cytotoxicity Assay}

In order to check the in vitro lytic activity of the differentiated NK cell against the K562 target cell line, we performed a calcein-AM-based cytotoxicity assay (26). K562 cell line was used as target cells. $10^{6}$ cells were incubated for $30 \mathrm{~min}$ at $37^{\circ} \mathrm{C}$ with $15 \mu \mathrm{M}$ of calcein-AM (Life technologies C3099). These cells were washed twice after incubation. Calcein-AM-labeled K562 cells were cocultured with NK cells differentiated from $\mathrm{CD} 34^{+}$progenitors from UCB in a U-bottom 96-well plate for $4 \mathrm{~h}$ at $37^{\circ} \mathrm{C}$ at different ratios $(25: 1,12.5: 1,6.25: 1$, and 3.125:1). As a control, we used NK cells from adult healthy donors' blood isolated with the NK Cell Isolation Kit from Miltenyi Biotec (catalog number 130-092-657). These adult PB-NK cells were stimulated overnight under the same conditions as our UCB $\mathrm{CD}_{3}{ }^{+}$in vitro differentiation protocol (IL-7, IL-15, SCF, and FLT3). Adult PB-NK cells were purified by MACS sorting, using the NK Cell Isolation Kit from Miltenyi Biotec (130-092-657). For measurement of spontaneous release, K562 target cells were incubated with no NK cells. Total released was achieved by adding 4\% Triton ${ }^{\mathrm{TM}} \mathrm{X}-100$ (Sigma-Aldrich) to the target cells. Each condition was performed in triplicates. After the incubation, $100 \mu \mathrm{l}$ of supernatant was collected and transferred to a black 96-well plate to measure the calcein-AM release in a Fluoroskan Ascent (Thermo Fisher) (excitation filter: $485 \pm 9 \mathrm{~nm}$; band-pass filter: $530 \pm 9 \mathrm{~nm}$ ). The percentage of specific lysis is calculated according to the following formula: [(Test release) - (Medium fluorescence $)]-[($ Spontaneous release $)-$ (Medium fluorescence $)] /[($ Total release $)-($ Triton fluorescence $)]-[$ (Spontaneous release $)-($ Medium fluorescence $)] \times 100$.

\section{Degranulation Assay}

Natural killer cells were cocultured with K562 target cells at ratio 1:1 in a 24 -well plate for $6 \mathrm{~h}$ at $37^{\circ} \mathrm{C}$. At the beginning of the assay, anti-CD107a BV421 (BD Biosciences, clone H4A3) was added in order to detect the degranulation activity of the effector cells against the target cells. Golgi Stop ${ }^{\mathrm{TM}}$ (BD Biosciences) (monensin) was added following the manufacturer's protocol. After the incubation, cells were collected, washed, and labeled with anti-CD94-FITC and anti-CD56-APC. Degranulating NK cells $\left(\mathrm{CD} 107 \mathrm{a}^{+}\right)$were determined in the $\mathrm{CD} 56^{+}$cells, both on stage 3 $\left(\mathrm{CD} 56^{+} \mathrm{CD} 94^{-}\right)$and stages $4-5\left(\mathrm{CD} 56^{+} \mathrm{CD} 94^{+}\right)$cells.

\section{Data Analysis}

Differences between groups were evaluated using paired Student's $t$-test. $p$-Values $<0.05$ were considered significant. Statistical calculations were done using GraphPad Prism 6 (GraphPad Software, Inc.) Bars represent the mean and error bars represent the SEM.

\section{RESULTS}

\section{OP9 Cell-Based Coculture System Generates Higher Numbers of CD56+ NK Cells than M2-10B4 Cell-Based Coculture System}

CD $34^{+}$UCB cells were cultured up to 42 days using the protocol described in Section "Materials and Methods." Cell number and percentage of $\mathrm{CD} 56^{+} \mathrm{NK}$ cells were checked weekly. CD $34^{+}$ UCB cocultured with OP9 cells feeder layer exhibited a better proliferative capacity as compared with $\mathrm{CD} 34^{+} \mathrm{UCB}$ cocultured with M2-10B4 cells feeder layer at day 21. In addition, we found a higher number of CD56 ${ }^{+} \mathrm{NK}$ cells with OP9 cells coculture at 28 days of differentiation $(p<0.05)$, reaching $2 \times 10^{7} \mathrm{NK}$ cells on average, while this number dropped in the next days. Meanwhile, the number of $\mathrm{CD}^{2} 6^{+}$cells in the M2-10B4 cells coculture condition increased gradually until 35 days of differentiation, reaching $1 \times 10^{7} \mathrm{NK}$ cells, and dropped slightly at 42 days of differentiation (Figure 1A). Similarly, we observed a higher frequency of $\mathrm{CD}^{2} 6^{+}$cells in the OP9 cells coculture than in the M2-10B4 cells coculture, with significant differences at day $21(p<0.001)$ and day $28(p<0.01)$ (Figure 1B). Likewise, we observed a higher fold expansion of $\mathrm{CD}^{2} 6^{+}$cells in the OP9 cells coculture condition, especially at day 28 of differentiation $(p<0.05)$ which correlates with the pattern followed by the number of $\mathrm{CD} 6^{+}$cells obtained (Figure 1C). Also, we perform a feeder-free culture condition. Our results showed that a very small number of NK cells were obtained in this culture condition (Figure S2 in Supplementary Material). We believe that the presence of the feeder layer is crucial for the correct differentiation of NK cells from $\mathrm{CD} 34^{+}$cells.

\section{The In Vitro Differentiation Pattern of NK Cells Resembles the In Vivo Differentiation Pattern}

According to the differentiation pattern from $\mathrm{CD} 34^{+} \mathrm{UCB}$ to mature $\mathrm{CD}_{5} 6^{+} \mathrm{CD}^{-} \mathrm{NK}$ cells in vivo (Figures S3 and S4 in Supplementary Material), key markers were selected in order to determine the in vitro differentiation pattern obtained under our differentiation protocols (27). Depending on the presence or absence of different markers, NK cells were classified in different stages (Stage < 3: CD56-, CD94- ${ }^{-}$, CD117 ${ }^{\text {low; }}$ Stage 3: CD56 ${ }^{+}$, $\mathrm{CD}_{4}^{-}{ }^{-}, \mathrm{CD} 16^{-}, \mathrm{CD} 117^{\text {high }}$; Stage 4: $\mathrm{CD} 56^{+}, \mathrm{CD}^{+} 4^{+}, \mathrm{CD} 16^{-}$, CD $117^{\text {low }}$, and Stage 5: $\left.\mathrm{CD}^{2} 6^{+}, \mathrm{CD} 94^{+}, \mathrm{CD} 16^{+}, \mathrm{CD} 117^{\text {low }}\right)$, which were determined according to the expression of the NK cell markers CD56 and CD94. The correct analysis of the stages was assured by the expression of the CD117 marker on NK cells. CD $56^{+} / \mathrm{CD} 94^{+}$population was divided in stages 4 and 5 based on the presence or absence of the CD16 marker. In this manuscript, 


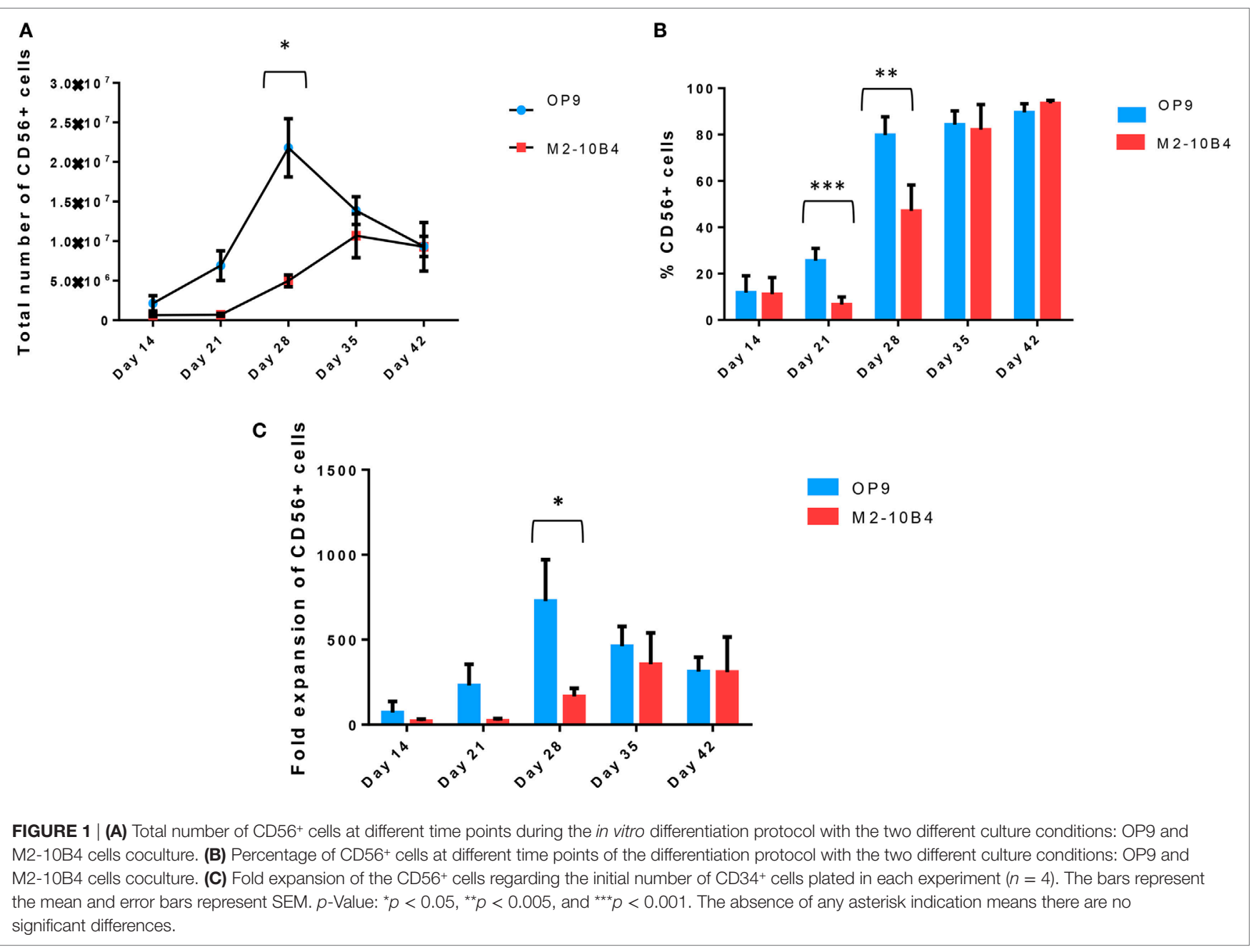

stages 4 and 5 were represented as stages $4-5$ in order to include mature NK cells in a single population.

The percentage of more mature NK cells increased over time during the in vitro differentiation protocol (Figure 2A), with higher percentage of more mature stages in culture conditions in the presence of OP9 cells in comparison with cultures in the presence of M2-10B4 cells. On the one hand, these more mature stages are reached earlier by the cells cocultured with the OP9 cell line than with the M2-10B4 cell line and the percentage of cells in the stages $4-5$ is maintained over time with the OP9 cell line, while it gets higher with the M2-10B4 (Figure 2B). On the other hand, the total number of cells at stages 4-5 of maturation equalizes between the two culture conditions at the end of the differentiation protocol, having more cells at day 28 with the culture condition using OP9 cells (Figure 2C).

\section{In Vitro-Generated NK Cells Exhibit Cytotoxic Activity}

Mature NK cells (stages 4 and 5) express cytolytic granules containing perforin and granzyme (28). We determined the expression of perforin and granzyme B in developing NK cells at days
28,35 , and 42 of the differentiation protocol. No significant differences in the expression of these two cytolytic markers were found between cells cultured with the OP9 cells layer in comparison with cells cultured with the M2-10B4 feeder cells. In both culture conditions, the percentage and the intensity of perforin expression in positive cells was higher than the expression of granzyme-B (Figures 3A,B). Moreover, the frequency of cells expressing perforin at days 28, 35, and 42 with OP9 cells feeder layer was very similar to the percentage of $\mathrm{CD} 56^{+}$ NK cells, as well as to the condition with M2-10B4 cells feeder layer at days 35 and 42 . We also found that in vitro differentiated NK cells did not show a significant difference in the expression of perforin and granzyme B between stage 3 and stages $4-5$ in both culture conditions (data not shown).

Next, we determined the degranulation capacity of the in vitrogenerated NK cells. To do that, we measured the expression of CD107a on NK cells after being stimulated with K562 target cells, according to the protocol described in Section "Materials and Methods." Activated NK cells from PB of healthy adult donors were used as a control (data not shown). At days 28, 35, and 42, the degranulation tended to be higher in NK cells generated with M2-10B4 feeder cells than in the NK cells generated in the 


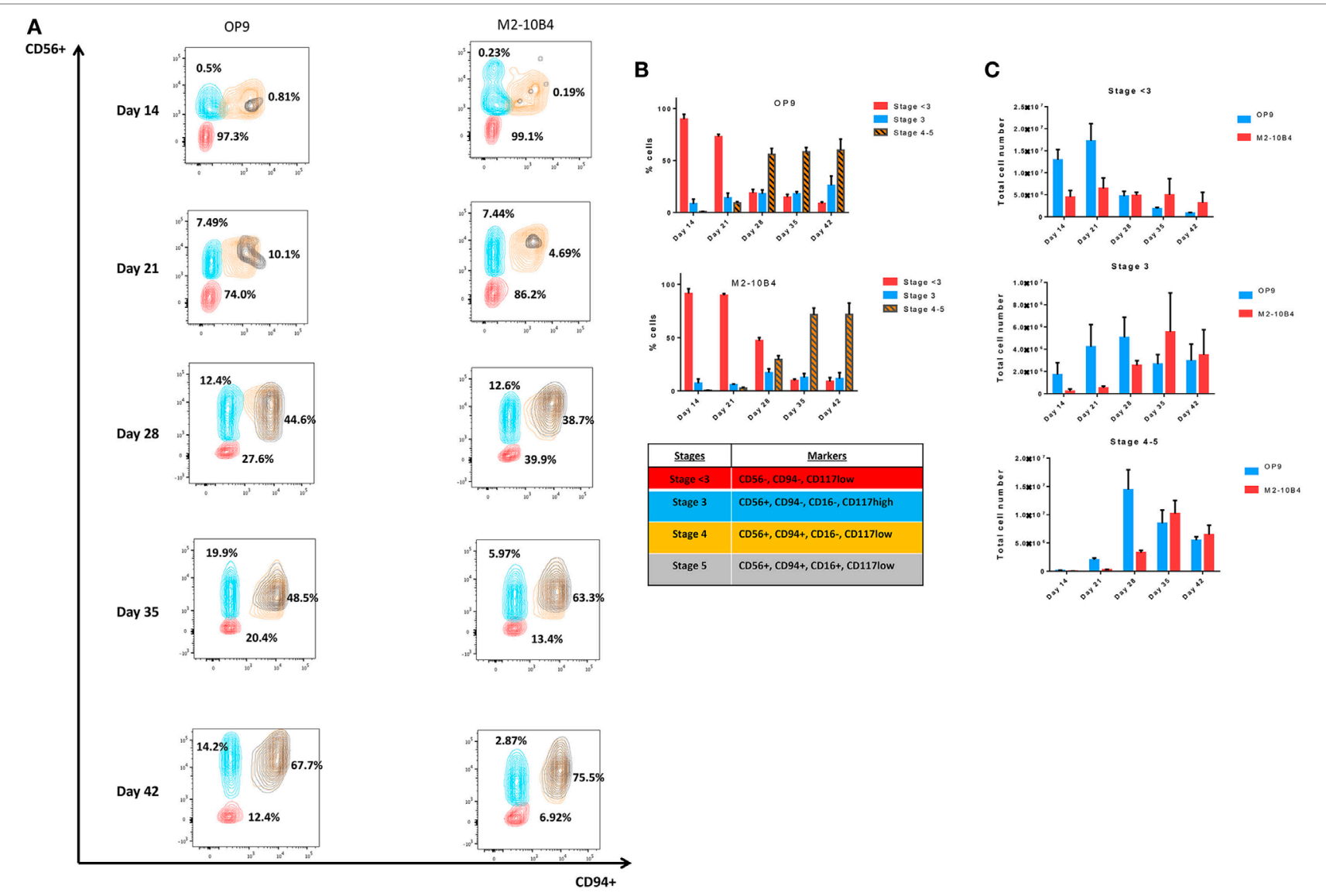

FIGURE 2 | (A) Contour plots representing the different natural killer (NK) cell maturation stages during the differentiation protocol using OP9 and M2-10B4 cells as feeder layers. CD94, CD56, and CD16 markers were analyzed to determine the maturation stage as described in the text. Numbers represent the percentage of cells in stage $<3$ (red), stage 3 (turquoise), and stages 4-5 (orange and black). (B) Percentage of NK cells in the different stages of maturation (<3, 3, and 4-5) along the differentiation time course. (C) Total number of cells in the different stages $(<3,3$, and $4-5)$ cultured with the two conditions: OP9 and M2-10B4 cells coculture. The bars represent the mean and error bars represent SEM (Stage <3: CD56-, CD94-, CD117low; Stage 3: CD56+, CD94-, CD16-, CD117 high; Stage 4: CD56+, CD94+, CD16-, CD117 low, and Stage 5: CD56+, CD94+, CD16+, CD117 low).

presence of OP9 feeder cells, although there were no significant differences (Figure 4A). We also analyzed the degranulation in the stage 3 and stages $4-5$ of the in vitro-generated NK cells. The degranulation in both culture conditions exhibited a very significant difference between stage 3 and stages 4-5 (Figure 4B). Finally, we tested the cytolytic activity of NK cells against the K562 target cells. NK cells purified and activated from adult PB were used as a control. At day 28, NK cells differentiated in the presence of OP9 cells were more cytotoxic than NK cells differentiated in the presence of M2-10B4 cells (Figure 4C). At days 35 and 42, the cytotoxic activity was similar in both culture conditions at several effector:target ratios (Figure 4C). However, at day 42, at ratio 25:1, NK cells differentiated in the presence of M2-10B4 cells were significantly more cytotoxic than the NK cells differentiated in the presence of OP9 cells.

\section{DISCUSSION}

In this study, we tested and compared the effect of two different culture conditions during the generation of in vitro functional and mature NK cells from HSC precursors from UCB. We show that by using OP9 cells as a feeder layer we obtained higher number of $\mathrm{CD}_{56}{ }^{+}$mature NK cells in comparison with M2-10B4 cells as a feeder layer. To date, several articles have described different protocols for in vitro $\mathrm{NK}$ cell differentiation from hematopoietic progenitors from UCB $\left(\mathrm{CD} 34^{+}\right.$cells) including the usage of different feeder cells, cytokine cocktails, and time of culture $(16,17,24,25,29-40)$. However, we believe that our study for the first time describes in detail the maturation stages of NK cells during the in vitro differentiation process in which a high number of functional NK cells are achieved with the possibility for using them in future immunotherapies against cancer.

We have described a new culture condition, using two cell lines as feeder layers, i.e., OP9 cells and M2-10B4 cells, to generate $\mathrm{NK}$ cells from $\mathrm{UCB} \mathrm{CD} 34^{+}$hematopoietic precursors.

Other authors have described the use of these two cell lines to differentiate $\mathrm{CD} 34^{+}$cells from pluripotent stem cells, such as ESCs and induced pluripotent stem cells $(12,18,19,21)$ and also to support and maintain CD $34^{+}$cells in a long-term culture $(41,42)$. 


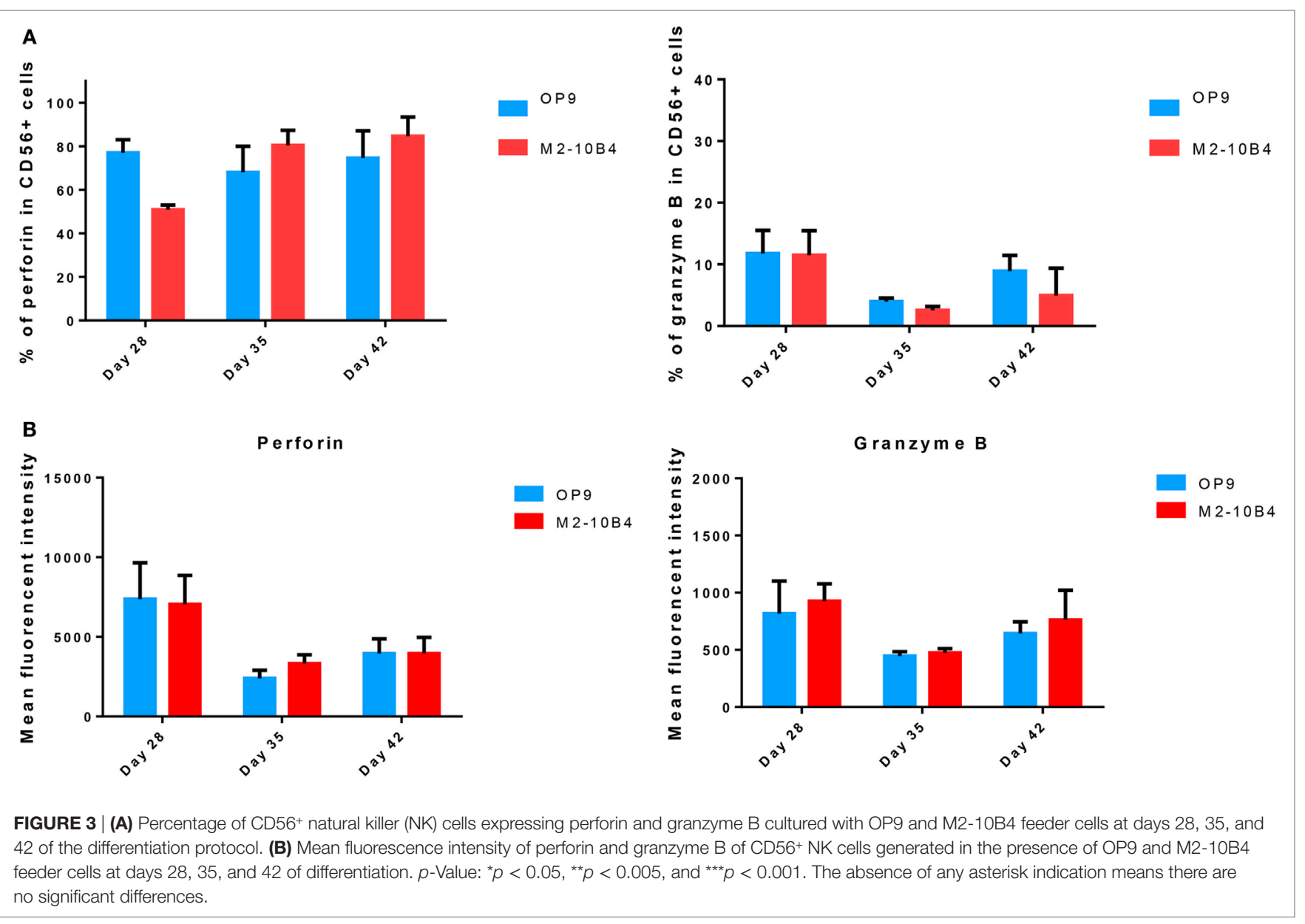

The use of feeder cell lines with the aim of maintenance and differentiation of stem cells toward blood lineage cells is an usual practice. First, the cell line AFT024 was described by Moore et al., immortalized with SV-40 T antigen, and derived from murine fetal liver stromal cells (43). Specifically, to study human NK cell ontogeny, Miller and McCullar suggested that NK cell differentiation from $\mathrm{CD} 34^{+}$cells and receptor acquisition was contact dependent with the feeder layer AFT024 (44). Other groups investigated the AFT024 and EL08-1D2 potential to generate in vitro NK cells and found that EL08-1D2 is significantly better at recapitulating NK cell development (39).

M2-10B4 is the other feeder cell line commonly used, and it derives from murine bone marrow stromal cells. M2-10B4 has been used earlier for NK cell expansion $(45,46)$ and others determined its differentiation potential for NK cell generation from hESCs (47). Remarkably, these findings suggest the need of stromal cell microenvironment, and the importance of direct contact with the feeder layer.

Finally, few reports have used the OP9 cell line $(38,40)$ to differentiate $\mathrm{NK}$ cells from bone marrow $\mathrm{CD} 34^{+}$cells. Also, OP9-DL1 (OP9 modified with Notch ligand delta-like 1) is used to develop T lymphocytes (48) and NK cells from hematopoietic precursors (49). To summarize, the majority of published data indicate the need of a microenvironment supported by stromal cells. This microenvironment provides necessary factors for the correct maturation of NK cells. Therefore, we wanted to explore new culture conditions to obtain high number of mature and functional NK cells from $\mathrm{UCB} \mathrm{CD} 4^{+}$cells, to improve the in vitro differentiation protocols previously published, and also to in detail characterize there in vitro development in comparison with the maturation stages described in vivo.

To do this, we have compared both cell lines (OP9 and M2-10B4) in terms of differentiation capacity, number of $\mathrm{CD} 56^{+}$cells and NK fold expansion from the first week up to 6 weeks of differentiation. In general, we have obtained higher number, fold expansion, and frequencies of $\mathrm{CD}^{2} 6^{+} \mathrm{NK}$ cells, specifically when they are generated in the presence of OP9 feeder cells, than other authors who have used similar protocols. For example, with the EL08.1D2 cell line as feeder cells, several groups have obtained a similar fold of expansion (16) or a lower number and frequency of $\mathrm{CD}_{56} 6^{+} \mathrm{NK}$ cells $(25,31,39)$ than us. Others have also obtained lower number or lower fold expansion when the AFT024 cell line (39) or Stro- $1^{+}$cell line (32) were used as feeder layers. In our study, using both cell lines (OP9 and M2-10B4), we get a higher number of NK cells with OP9 cell line. Importantly, we have also obtained higher number and frequencies of CD56 ${ }^{+}$ NK cells than others who have also used OP9 cells as feeder layer $(38,40)$. 


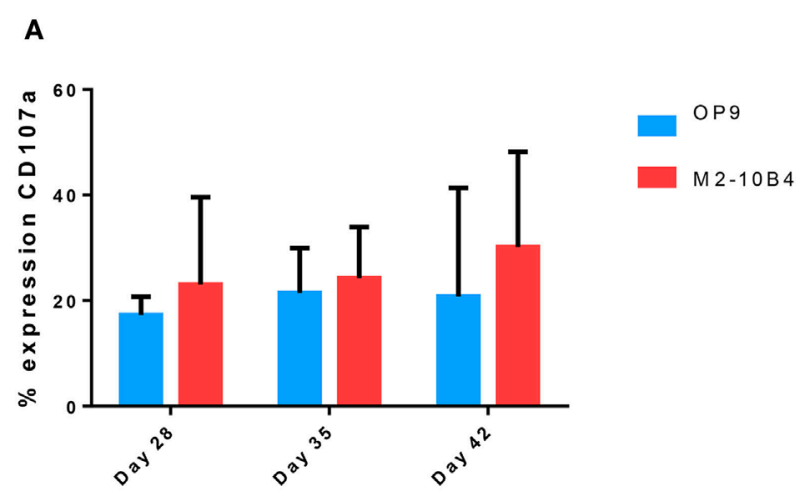

B

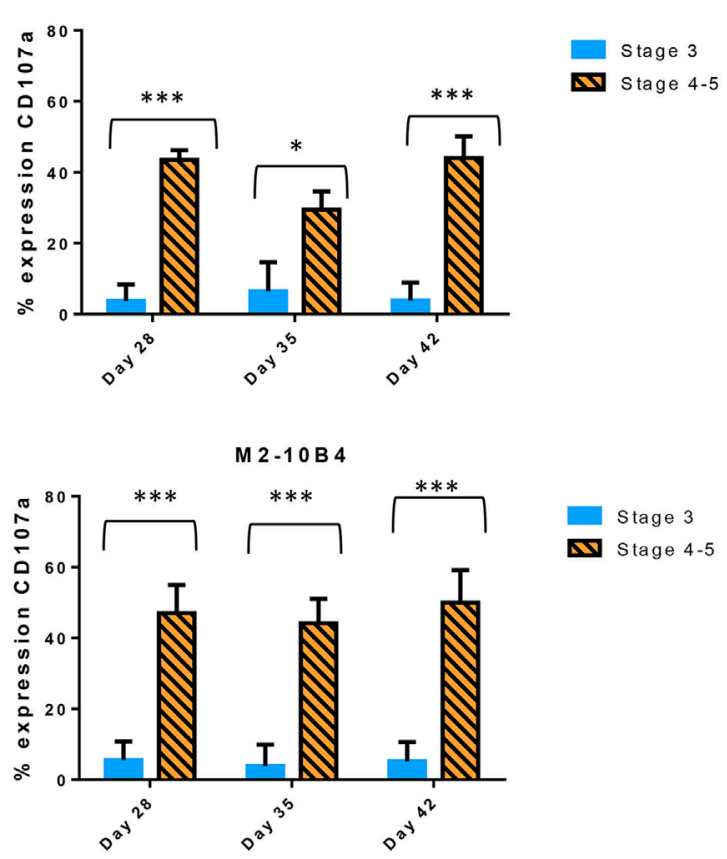

C

CYTOTOXICITY DAY 28
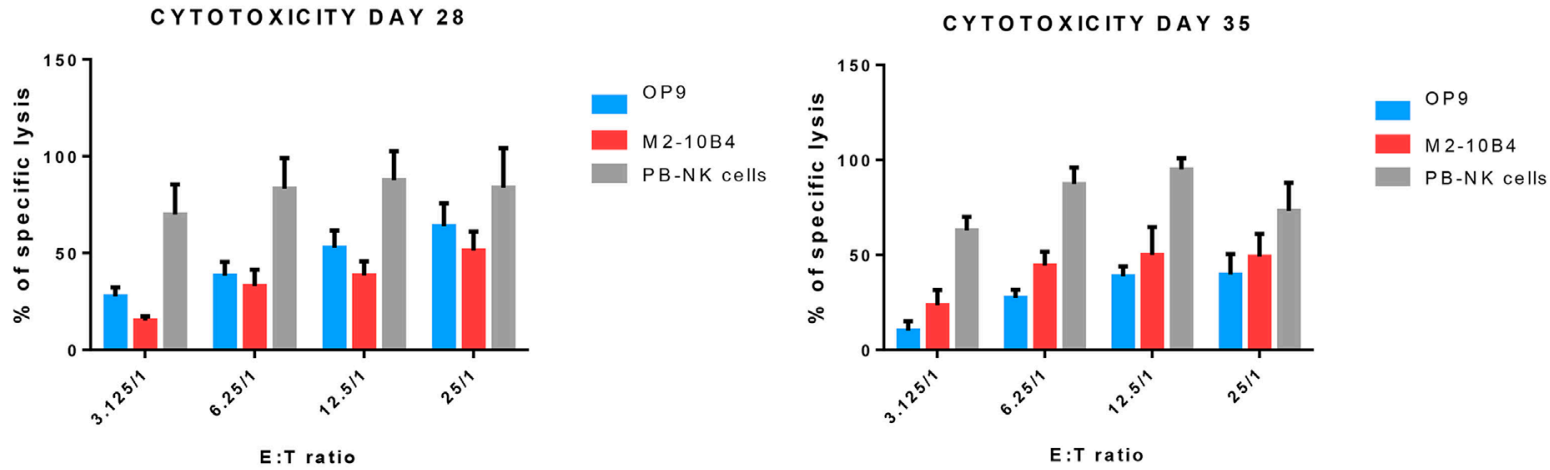

CYTOTOXICITY DAY 42

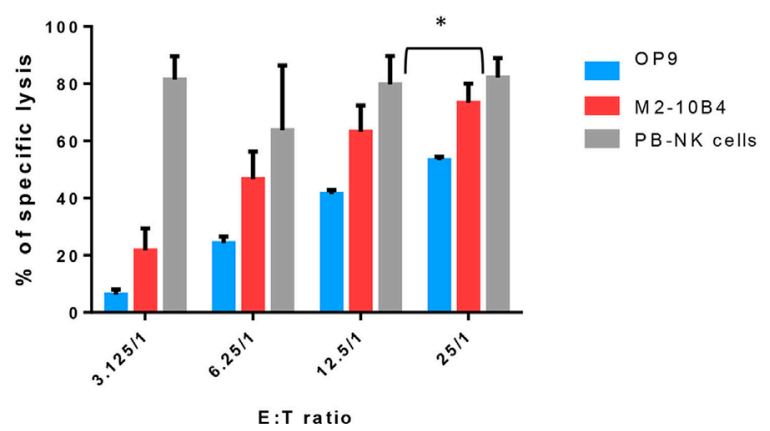

FIGURE 4 | (A) Expression of CD107a, a marker of degranulation, in the in vitro-generated natural killer (NK) cells (CD56+) at different time points of the differentiation protocol in response to the stimulation with K562 target cells. (B) Expression of CD107a in both conditions (with OP9 and M2-10B4 feeder cell layers) at stage 3 and stages $4-5$ at different times of the differentiation protocol. (C) Cytotoxicity activity of NK cells against K562 target cells at days 28, 35, and 42 of the differentiation protocol. Overnight cultured NK cells obtained from adult peripheral blood stimulated with the same cytokines as our in vitro-generated NK cells were used as a control. The bars represent the mean and error bars represent SEM. $p$-Value: ${ }^{*} p<0.05 ;{ }^{* \star *} p<0.001$. The absence of any asterisk indication means there

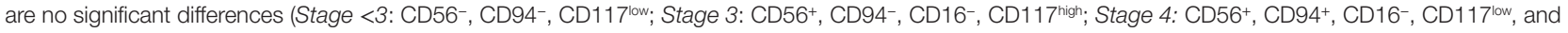
Stage 5: $\left.\mathrm{CD}^{+} 6^{+}, \mathrm{CD}^{+} 4^{+}, \mathrm{CD} 16^{+}, \mathrm{CD} 117^{\mathrm{lom}}\right)$. 
Currently, the vast majority of researchers accept a linear model of differentiation of human NK cells with five stages of maturation, each characterized by a pattern of expression of surface receptors, functional capabilities, and differentiation potential (27). In stage 3, cells have variable expression of the markers CD161 and CD56, typical of mature NK cells, but they do not express inhibitory receptors for MHC class I molecules, i.e., KIR and CD94/NKG2A, which they are characteristic of mature NK cells. In addition, cells in stage 3 have the two signs of functional identity of mature NK cells: IFN- $\gamma$ production and perforin-dependent cytotoxic activity. CD94 expression marks the transition to stage 4 in the development of human NK cells. Cells at this stage are characterized by high CD56 expression. The acquisition of CD16 in some CD94 $4^{+}$cells is considered a marker of cells in stage 5 , the group defined by the phenotype CD94 ${ }^{\text {high }} \mathrm{CD} 56^{\mathrm{dim}} \mathrm{CD} 16^{+}$cells. Therefore, CD56 ${ }^{\mathrm{dim}}$ and CD56 $6^{\text {bright }}$ cells in $\mathrm{PB}$ represent the two terminal stages of differentiation of human NK cells (50).

We have observed that our in vitro differentiation and maturation process of NK cells follows a similar pattern regarding the surface markers acquisition, which are observed in vivo. For example, CD117 expression in our in vitro NK cells is always present in late stages $(4,5)$, whereas is downregulated in in vivo differentiated NK cells at stage 5 . We believe this is due to the presence of SCF in our culture system, as it has been reported that the presence of this cytokine upregulates the expression of CD117 in CD56 ${ }^{+} \mathrm{NK}$ cells and significantly increases the capacity of CD56 $6^{\text {bright }} \mathrm{NK}$ cells to degranulate (51). In our cultures, we cannot distinguish between CD56 ${ }^{\mathrm{dim}}$ and CD56 $6^{\text {bright }} \mathrm{NK}$ cells, which probably are due to the fact that this in vitro phenotype is slightly different to the in vivo due to the culture conditions.

We observed differences in maturation stages between the two cell lines used as feeder layers. More mature stages are reached earlier by using OP9 cell line than with the M2-10B4 cell line. Otherwise, the total number of cells at stages 4-5 of maturation equalizes between the two conditions at the end of the differentiation protocol, having more NK cells at day 28 when the culture conditions include the OP9 feeder cells, which also may be responsible for the observed higher cytotoxicity activity. We think that these differences in timing of maturation and number is due to the NK cell differentiation potential properties among stromal cell lines used in this study, because it has been reported that depending of the origin of the stromal cell lines used in hematopoietic differentiation, the features of maturation, and functionality of the terminal cell type could be different (52).

Few groups have described the in vitro developed NK cells in the presence of OP9 feeder cells. First, it has been reported that using OP9 cell line (38) during the in vitro development of $\mathrm{NK}$ cells from bone marrow or $\mathrm{UCB} \mathrm{CD} 34^{+}$cells, the levels of TGF- $\beta$ may influence the developmental progression and subset formation of NK cells, like $\mathrm{CD} 56^{\text {bright }} \mathrm{CD} 16^{-}$subset, but there are no studies in the progression of NK stages in vitro. Second, other group (40) also using OP9 feeder cells, obtained $80 \%$ of CD56 ${ }^{+}$ cells at 28 days, but they did not distinguish between different stages of maturation. In our case, we are able to achieve $70-80 \%$ of $\mathrm{CD}^{2} 6^{+}$cells at the same day of differentiation but we studied in detail that around $38-45 \%$ of $\mathrm{CD}^{2} 6^{+}$cells are already in stages 4-5, showing the typical markers of mature NK cells. Besides, other groups using other culture conditions achieved a minor percentage of $\mathrm{CD}^{+} 6^{+}$cells in stages more immature than we did $(16,36)$.

In general, we have also obtained better or similar results than others when we look at the expression of cytolytic markers, degranulation properties, and killing activity of in vitro-generated NK cells. For example, in feeder-free systems, in vitro-generated NK cells expressed lower levels of perforin $(34,36)$, lower (36) or equal (35) cytotoxic activity, and equal levels of granzyme B (36) and degranulation potential $(29,30)$. When NK cells were generated in the presence of the EL08.1D2, they exhibited similar levels of perforin and granzyme B (16), similar degranulation levels $(16,33)$, and lower cytotoxic activity (25). Finally, in a study where OP9 feeder cells were used for the differentiation of NK cells, the authors found that they expressed lower levels of perforin (40) compared with the NK cells we obtained in our study.

In conclusion, we found that the use of OP9 and M2-10B4 cell

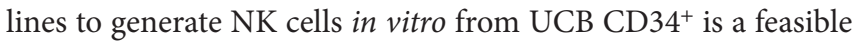
option that offers the advantage of obtaining higher functional and mature NK cell numbers with enhanced killing capacity. To the best of our knowledge, this is the first and the most comprehensive study comparing these two culture conditions for the generation of NK cells from fresh $\mathrm{UCB} \mathrm{CD} 34^{+}$cells, being OP9 cells culture condition better than M2-10B4 cells, highlighting the great potential for $\mathrm{UCB} \mathrm{CD}^{+} 4^{+}$for future NK cell-based immunotherapy.

\section{ETHICS STATEMENT}

This study was carried out in accordance with the recommendations and approval of "Basque Ethics Committee for Clinical Research [Comité Etico de Investigación Clinica de EuskadiCEIC-E (PI2014138)]" with written informed consent from all subjects in accordance with the Declaration of Helsinki.

\section{AUTHOR CONTRIBUTIONS}

LH: collection and/or assembly of data, data analysis and interpretation, and manuscript writing. JS: collection and/or assembly of data and data analysis. SS: data analysis and interpretation. MV: final approval of manuscript and financial support. FB: conception and design, data analysis and interpretation, manuscript writing, and final approval of manuscript. CE: conception and design, collection and/or assembly of data, data analysis and interpretation, manuscript writing, and final approval of manuscript.

\section{ACKNOWLEDGMENTS}

We apologize to our colleagues whose work was not cited due to space limitations. We thank the Basque Biobank for Research (Biobanco Vasco) for the collection of the samples. 


\section{FUNDING}

This work was supported by SAIOTEK, Basque Government (Grant SAIO13-PE13BF006) and Maratón EiTB-Cancer Infantil (BIO13/CI/009). LH was supported by Jesus Gangoiti Barrera Foundation and Asociación Española contra el Cáncer (AECC); JS was supported by Spanish Ministry of Economy and Competitiveness (MINECO) (PTA2013-8458-I).

\section{SUPPLEMENTARY MATERIAL}

The Supplementary Material for this article can be found online at http://journal.frontiersin.org/article/10.3389/fimmu.2017.00755/ full\#supplementary-material.

\section{REFERENCES}

1. Gras Navarro A, Björklund AT, Chekenya M. Therapeutic potential and challenges of natural killer cells in treatment of solid tumors. Front Immunol (2015) 6:202. doi:10.3389/fimmu.2015.00202

2. Prabhu SB, Rathore DK, Nair D, Chaudhary A, Raza S, Kanodia P, et al. Comparison of human neonatal and adult blood leukocyte subset composition phenotypes. PLoS One (2016) 11(9):e0162242. doi:10.1371/journal. pone.0162242

3. Santos SV, Barros SM, Santos MS, Marti LC, Ribeiro AA, Kondo AT, et al. Predictors of high-quality cord blood units. Transfusion (2016) 56(8):2030. doi:10.1111/trf.13653

4. Caligiuri MA. Human natural killer cells. Blood(2008) 112(3):461. doi:10.1182/ blood-2007-09-077438

5. Cortez VS, Colonna M. Diversity and function of group 1 innate lymphoid cells. Immunol Lett (2016) 179:19. doi:10.1016/j.imlet.2016.07.005

6. Ferlazzo G, Thomas D, Lin SL, Goodman K, Morandi B, Muller WA, et al. The abundant NK cells in human secondary lymphoid tissues require activation to express killer cell Ig-like receptors and become cytolytic. J Immunol (2004) 172:1455-62. doi:10.4049/jimmunol.172.3.1455

7. Foley B, Felices M, Cichocki F, Cooley S, Verneris M, Miller J. The biology of NK cells and their receptors affects clinical outcomes after hematopoietic cell transplantation (HCT). Immunol Rev (2014) 258(1):45. doi:10.1111/imr.12157

8. Yu J, Freud A, Caligiuri M. Location and cellular stages of natural killer cell development. Trends Immunol (2013) 34(12):3573. doi:10.1016/j.it.2013. 07.005

9. Borrego F, Larrucea S, Solana R, Tarazona R. Editorial: NK cell-based cancer immunotherapy. Front Immunol (2016) 27(7):249. doi:10.3389/ fimmu.2016.00249

10. Zenarruzabeitia O, Vitallé J, Astigarraga I, Borrego F. Natural killer cells to the attack: combination therapy against neuroblastoma. Clin Cancer Res (2017) 23(3):615. doi:10.1158/1078-0432.CCR-16-2478

11. Becker PS, Suck G, Nowakowska P, Ullrich E, Seifried E, Bader P, et al. Selection and expansion of natural killer cells for NK cell-based immunotherapy. Cancer Immunol Immunother (2016) 65(4):477. doi:10.1007/s00262-016-1792-y

12. Eguizabal C, Zenarruzabeitia O, Monge J, Santos S, Vesga MA, Maruri N, et al. Natural killer (NK) cells for immunotherapy: a special case for pluripotent stem cells-derived NK cells. Front Immunol (2014) 15(5):439. doi:10.3389/ fimmu.2014.00439

13. Pérez-Martínez A, Fernández L, Valentín J, Martínez-Romera I, Corral MD, Ramírez M, et al. A phase I/II trial of interleukin-15 stimulated natural killer cell infusion after haplo-identical stem cell transplantation for pediatric refractory solid tumors. Cytotherapy (2015) 17(11):1594. doi:10.1016/j. jcyt.2015.07.011

14. Granzin M, Stojanovic A, Miller M, Childs R, Huppert V, Cerwenka A. Highly efficient IL-21 and feeder cell-driven ex vivo expansion of human NK cells with therapeutic activity in a xenograft mouse model of melanoma. Oncoimmunology (2016) 5(9):e1219007. doi:10.1080/2162402X.2016.1219007

15. Mehta RS, Shpall EJ, Rezvani K. Cord blood as a source of natural killer cells. Front Med (2016) 2:93. doi:10.3389/fmed.2015.00093
TABLE S1 | Number of fresh umbilical cord blood (UCB) units, volume in milliliters, number of mononuclear cells per UCB, and CD34+ ${ }^{+}$cells remaining after purification for each experiment. UCB were fresh, being not longer than $30 \mathrm{~h}$ after the extraction.

FIGURE S1 | (A) Purity of CD34+ cell population from umbilical cord blood (UCB) obtained by immunomagnetic isolation. (B) Remaining percentage of $\mathrm{CD}^{+} 6^{+}$cells after purification of $\mathrm{CD} 34^{+}$cells from $\mathrm{UCB}$

FIGURE S2 | Total number of $\mathrm{CD}^{2} 6^{+}$cells at different time points during the in vitro differentiation protocol with three different culture conditions: OP9 and M2-10B4 cells coculture (N:4) and feeder-free ( $N: 2)$.

FIGURE S3 | Key markers expressed at different stages through natural killer cell differentiation/maturation in vivo and in vitro.

FIGURE S4 | Dot-plots of the expression of CD3 at different stages of natural killer cells during the differentiation protocol.

16. Luevano M, Domogala A, Blundell M, Jackson N, Pedroza-Pacheco I, Derniame S, et al. Frozen cord blood hematopoietic stem cells differentiate into higher numbers of functional natural killer cells in vitro than mobilized hematopoietic stem cells or freshly isolated cord blood hematopoietic stem cells. PLoS One (2014) 9:e87086. doi:10.1371/journal.pone. 0087086

17. Cany J, van der Waart AB, Tordoir M, Franssen GM, Hangalapura BN, de Vries J, et al. Natural killer cells generated from cord blood hematopoietic progenitor cells efficiently target bone marrow-residing human leukemia cells in NOD/SCID/IL2Rg(null) mice. PLoS One (2013) 8(6):e64384. doi:10.1371/ journal.pone.0064384

18. Laskowski TJ, Van Caeneghem Y, Pourebrahim R, Ma C, Ni Z, Garate Z, et al. Gene correction of iPSCs from a Wiskott-Aldrich syndrome patient normalizes the lymphoid developmental and functional defects. Stem Cell Reports (2016) 7(2):139. doi:10.1016/j.stemcr.2016.06.003

19. Kim EM, Manzar G, Zavazava N. Human iPS cell-derived hematopoietic progenitor cells induce T-cell anergy in in vitro-generated alloreactive CD8(+) T cells. Blood (2013) 121(26):5167. doi:10.1182/ blood-2012-11-467753

20. Tabatabaei-Zavareh N, Vlasova A, Greenwood CP, Takei F. Characterization of developmental pathway of natural killer cells from embryonic stem cells in vitro. PLoS One (2007) 2(2):e232. doi:10.1371/journal.pone.0000232

21. Kaufman DS. Toward clinical therapies using hematopoietic cells derived from human pluripotent stem cells. Blood (2009) 114(17):3513. doi:10.1182/ blood-2009-03-191304

22. Ferrell PI, Hexum MK, Kopher RA, Lepley MA, Gussiaas A, Kaufman DS. Functional assessment of hematopoietic niche cells derived from human embryonic stem cells. Stem Cells Dev (2014) 23(12):1355. doi:10.1089/scd. 2013.0497

23. Ni Z, Knorr DA, Kaufman DS. Hematopoietic and nature killer cell development from human pluripotent stem cells. Methods Mol Biol (2013) 1029:33. doi:10.1007/978-1-62703-478-4_3

24. Cichocki F, Miller JS. In vitro development of human killer-immunoglobulin receptor-positive NK cells. Methods Mol Biol (2010) 612:15-26. doi:10.1007/978-1-60761-362-6_2

25. Grzywacz B, Kataria N, Kataria N, Blazar BR, Miller JS, Vemeris MR. Natural killer-cell differentiation by myeloid progenitors. Blood (2011) 117(13):3548. doi:10.1182/blood-2010-04-281394

26. NeriS, Mariani E, Meneghetti A, Cattini L, Facchini A. Calcein-acetyoxymethyl cytotoxicity assay: standardization of a method allowing additional analyses on recovered effector cells and supernatants. Clin Diagn Lab Immunol (2001) 8(6):1131-5. doi:10.1128/CDLI.8.6.1131-1135.2001

27. Freud AG, Yu J, Caligiuri MA. Human natural killer cell development in secondary lymphoid tissues. Semin Immunol (2014) 26(2):132-7. doi:10.1016/j. smim.2014.02.008

28. Golden-Mason L, Rosen HR. Natural killer cells: multi-faceted players with key roles in hepatitis C immunity. Immunol Rev (2013) 255(1):68. doi:10.1111/ imr. 12090

29. Spanholtz J, Preijers F, Tordoir M, Trilsbeek C, Paardekooper J, de Witte T, et al. Clinical-grade generation of active NK cells from cord blood hematopoietic 
progenitor cells for immunotherapy using a closed-system culture process. PLoS One (2011) 6(6):e20740. doi:10.1371/journal.pone.0020740

30. Spanholtz J, Tordoir M, Eissens D, Preijers F, van der Meer A, Joosten I, et al. High log-scale expansion of functional human natural killer cells from umbilical cord blood CD34-positive cells for adoptive cancer immunotherapy. PLoS One (2010) 5(2):e9221. doi:10.1371/journal.pone.0009221

31. Dezell SA, Ahn YO, Spanholtz J, Wang H, Weeres M, Jackson S, et al. Natural killer cell differentiation from hematopoietic stem cells: a comparative analysis of heparin- and stromal cell-supported methods. Biol Blood Marrow Transplant (2012) 18(4):536. doi:10.1016/j.bbmt.2011.11.023

32. Frias AM, Porada CD, Crapnell KB, Cabral JM, Zanjani ED, Almeida-Porada G. Generation of functional natural killer and dendritic cells in a human stromalbased serum-free culture system designed for cord blood expansion. Exp Hematol (2008) 36(1):61-8. doi:10.1016/j.exphem.2007.08.031

33. Domogala A, Madrigal JA, Saudemont A. Cryopreservation has no effect on function of natural killer cells differentiated in vitro from umbilical cord blood CD34(+) cells. Cytotherapy (2016) 18(6):754. doi:10.1016/j. jcyt.2016.02.008

34. Ambrosini P, Loiacono F, Conte R, Moretta L, Vitale C, Mingari MC. IL-1 $\beta$ inhibits ILC3 while favoring NK-cell maturation of umbilical cord blood CD34(+) precursors. Eur J Immunol (2015) 45(7):2061. doi:10.1002/ eji.201445326

35. Lehmann D, Spanholtz J, Osl M, Tordoir M, Lipnik K, Bilban M, et al. Ex vivo generated natural killer cells acquire typical natural killer receptors and display a cytotoxic gene expression profile similar to peripheral blood natural killer cells. Stem Cells Dev (2012) 21(16):2926. doi:10.1089/scd.2011.0659

36. Zamai L, Del Zotto G, Buccella F, Galeotti L, Canonico B, Luchetti F, et al. Cytotoxic functions and susceptibility to apoptosis of human CD56(bright) NK cells differentiated in vitro from CD $34^{+}$hematopoietic progenitors. Cytometry A (2012) 81(4):294. doi:10.1002/cyto.a.22025

37. Pinho MJ, Punzel M, Sousa M, Barros A. Ex vivo differentiation of natural killer cells from human umbilical cord blood CD34+ progenitor cells. Cell Commun Adhes (2011) 18(3):45. doi:10.3109/15419061.2011.610911

38. Allan DS, Rybalov B, Awong G, Zúñiga-Pflücker JC, Kopcow HD, Carlyle JR, et al. TGF- $\beta$ affects development and differentiation of human natural killer cell subsets. Eur J Immunol (2010) 40(8):2289. doi:10.1002/eji.200939910

39. McCullar V, Oostendorp R, Panoskaltsis-Mortari A, Yun G, Lutz CT, Wagner JE, et al. Mouse fetal and embryonic liver cells differentiate human umbilical cord blood progenitors into CD56-negative natural killer cell precursors in the absence of interleukin-15. Exp Hematol (2008) 36(5):598-608. doi:10.1016/j.exphem.2008.01.001

40. Beck RC, Padival M, Yeh D, Ralston J, Cooke KR, Lowe JB. The Notch ligands Jagged2, Delta1, and Delta 4 induce differentiation and expansion of functional human NK cells from CD34+ cord blood hematopoietic progenitor cells. Biol Blood Marrow Transplant (2009) 15(9):1026. doi:10.1016/j.bbmt.2009. 06.002

41. Fernández-Sánchez V, Pelayo R, Flores-Guzmán P, Flores-Figueroa E, Villanueva-Toledo J, Garrido E, et al. In vitro effects of stromal cells expressing different levels of Jagged-1 and Delta- 1 on the growth of primitive and intermediate CD34(+) cell subsets from human cord blood. Blood Cells Mol Dis (2011) 47(4):205. doi:10.1016/j.bcmd.2011.08.003
42. Sakashita K, Kato I, Daifu T, Saida S, Hiramatsu H, Nishinaka Y, et al. In vitro expansion of $\mathrm{CD} 34(+) \mathrm{CD} 38(-)$ cells under stimulation with hematopoietic growth factors on AGM-S3 cells in juvenile myelomonocytic leukemia. Leukemia (2015) 29(3):606. doi:10.1038/leu.2014.239

43. Moore KA, Ema H, Lemischka IR. In vitro maintenance of highly purified, transplantable hematopoietic stem cells. Blood (1997) 89:4337-47.

44. Miller JS, McCullar V. Human natural killer cells with polyclonal lectin and immunoglobulinlike receptors develop from single hematopoietic stem cells with preferential expression of NKG2A and KIR2DL2/L3/S2. Blood (2001) 98:705-13. doi:10.1182/blood.V98.3.705

45. Pierson BA, McGlave PB, Hu WS, Miller JS. Natural killer cell proliferation is dependent on human serum and markedly increased utilizing an enriched supplemented basal medium. J Hematother (1995) 4:149-58. doi:10.1089/ scd.1.1995.4.149

46. Pierson BA, Gupta K, Hu WS, Miller JS. Human natural killer cell expansion is regulated by thrombospondin-mediated activation of transforming growth factorbeta 1 and independent accessory cell-derived contact and soluble factors. Blood (1996) 87:180-9.

47. Woll PS, Martin CH, Miller JS, Kaufman DS. Human embryonic stem cellderived NK cells acquire functional receptors and cytolytic activity. J Immunol (2005) 175:5095-103. doi:10.4049/jimmunol.175.8.5095

48. Kaneko $\mathrm{S}$. In vitro generation of antigen-specific $\mathrm{T}$ cells from induced pluripotent stem cells of antigen-specific T cell origin. Methods Mol Biol (2016) 1393:67. doi:10.1007/978-1-4939-3338-9-6

49. Kyoizumi S, Kubo Y, Kajimura J, Yoshida K, Imai K, Hayashi T, et al. Age-associated changes in the differentiation potentials of human circulating hematopoietic progenitors to T- or NK-lineage cells. J Immunol (2013) 190(12):6164. doi:10.4049/jimmunol.1203189

50. Ullrich E, Salzmann-Manrique E, Bakhtiar S, Bremm M, Gerstner S, Herrmann E, et al. Relation between acute GVHD and NK cell subset reconstitution following allogeneic stem cell transplantation. Front Immunol (2016) 22(7):595. doi:10.3389/fimmu.2016.00595

51. Pradier A, Tabone-Eglinger S, Huber V, Bosshard C, Rigal E, Wehrle-Haller B, et al. Peripheral blood CD56 (bright) NK cells respond to stem cell factor and adhere to its membrane-bound form after upregulation of c-kit. Eur J Immunol (2014) 44(2):511. doi:10.1002/eji.201343868

52. Ledran MH, Krassowska A, Armstrong L, Dimmick I, Renström J, Lang R, et al. Efficient hematopoietic differentiation of human embryonic stem cells on stromal cells derived from hematopoietic niches. Cell Stem Cell (2008) 3(1):85. doi:10.1016/j.stem.2008.06.001

Conflict of Interest Statement: The authors declare that the research was conducted in the absence of any commercial or financial relationships that could be construed as a potential conflict of interest.

Copyright $\odot 2017$ Herrera, Salcedo, Santos, Vesga, Borrego and Eguizabal. This is an open-access article distributed under the terms of the Creative Commons Attribution License (CC BY). The use, distribution or reproduction in other forums is permitted, provided the original author(s) or licensor are credited and that the original publication in this journal is cited, in accordance with accepted academic practice. No use, distribution or reproduction is permitted which does not comply with these terms. 